\title{
Biogranulation and Physical Properties of Aerobic Granules in Reactors at Low Organic Loading Rate and with Powdered Ceramsite Added
}

\author{
Joanna Czarnota ${ }^{1 *}$, Adam Masłoń $^{1}$ \\ Department of Environmental Engineering and Chemistry, Rzeszow University of Technology, Powstańców \\ Warszawy 6, 35-959 Rzeszów, Poland \\ Corresponding author's e-mail: askalucz@prz.edu.pl
}

\begin{abstract}
In wastewater treatment, aerobic granular sludge (AGS) technology is a relatively new alternative to the activated sludge method. The biogranulation of biomass ensues when appropriate environmental conditions in a reactor are ensured, and one of the factors determining this is the organic loading rate (OLR). As a literature review suggests, the optimal values of OLR for AGS technology are in the range of $2.50-7.50 \mathrm{~g} \mathrm{COD} /\left(\mathrm{dm}^{3} \cdot \mathrm{d}\right)$, the aim of the work detailed here was to evaluate the impact of powdered ceramsite on biogranulation in two Granular Sequencing Batch Reactors (GSBRs) in which OLR was equal to just $2.10 \mathrm{~g} \mathrm{COD} /\left(\mathrm{dm}^{3} \cdot \mathrm{d}\right)(\mathrm{R} 1)$ and $1.0 \mathrm{~g} \mathrm{COD} /\left(\mathrm{dm}^{3} \cdot \mathrm{d}\right)(\mathrm{R} 2)$. The research was carried out in laboratory scale with using synthetic wastewater containing different concentration of organic compounds. In the course of the research, a more intensive process of biogranulation was noted in reactor R1, and mean diameters of granules on the last day of experimentation were 962 and $274 \mu \mathrm{m}$ for R1 and R2, respectively. While the organic loading rate equal to $2.10 \mathrm{~g} \mathrm{COD} /\left(\mathrm{dm}^{3} \cdot \mathrm{d}\right)$ could allow granule formation, the results also pointed that lower food-to-microorganism (F/M) ratios favour biogranulation. This parameter was indirectly affected by the application of powdered ceramsite, because the powdered material improved the sludge sedimentation properties (average values of $\mathrm{SVI}_{30}$ being $30.1 \pm 12.8$ and $36.9 \pm 10.9 \mathrm{~cm}^{3} / \mathrm{g}$ ). The result of this was more-limited leaching of biomass from reactors (with average values for MLVSS at $4.37 \pm 1.23$ and $\left.3.03 \pm 0.67 \mathrm{~g} / \mathrm{dm}^{3}\right)$.
\end{abstract}

Keywords: aerobic granular sludge, powdered ceramsite, biogranulation, organic loading rate

\section{INTRODUCTION}

Aside from activated sludge and biofilm, aerobic granular sludge (AGS) represents a third form by which microbial aggregation takes place in the context of wastewater treatment. The efforts to encourage biomass to assume the form of aerobic granules are thus considered among the most-promising new biotechnologies in wastewater treatment [Long et al., 2019; Sguanci et al., 2019]. Compact structure, high settling capacity, tolerance to high organic load as well as a potential to remove carbon, nitrogen and phosphorus compounds simultaneously are all major advantages of this technology [Zou et al., 2019].
However, biogranulation is such a complicated matter that there is no full clarification of the mechanisms by which aerobic granules form [Long et al., 2019]. The operating conditions underpinning biogranulation are limited by many parameters, including seed sludge, a feast-famine regime, settling time, the volume exchange ratio, cycle time, the concentration of organic compounds in wastewater, organic loading rate, and other environmental conditions [He et al., 2016].

Most AGS processes have been used to treated medium- or high-strength wastewater, with organic loading rates in the range of 2.5-15.0 g COD $/\left(\mathrm{dm}^{3} \cdot \mathrm{d}\right)$. Previous studies have shown what values for OLR facilitate the granule 
formation [Sheng et al., 2010; Zhou et al., 2015]. According to a literature review, the optimal OLR with AGS technology should be of between 2.50 and $7.50 \mathrm{~g} \mathrm{COD} /\left(\mathrm{dm}^{3} \cdot \mathrm{d}\right.$ ) [Kim et al., 2008; Sarma et al., 2017; Czarnota et al., 2018]; where OLR is low, the granules become hard to cultivate. The problem here lies in the time needed for the granules to form and achieve an appropriate volume share within the reactor. This has had its impact on the ways the AGS-based systems have developed, as well as on their consistent operation, and on the efficiency of wastewater treatment achieved [Li et al., 2011; Sguanci et al., 2019].

In the research by Derlon et al. (2016), an OLR equal to $0.4 \pm 0.2 \mathrm{~g} \mathrm{COD} /\left(\mathrm{dm}^{3} \cdot \mathrm{d}\right)$ provided for the appearance of granules after 3 months. They were small, with a $30 \%$ fraction of the flocs present in the sludge. In turn, Zhang et al. (2011) reported that with an OLR equal to $0.58 \mathrm{~g} \mathrm{COD} /\left(\mathrm{dm}^{3} \cdot \mathrm{d}\right)$, the granules that formed were of loose, porous and hollow structure. Furthermore, such granules became unstable when their diameter increased above just $1 \mathrm{~mm}$.

For their part, Zou et al. (2019) indicated that the long startup time remains one of the main challenges in making AGS technologies work in practice. In this context, the research is paying much attention to the improvement of the biogranulation process. For example, acceleration of this process and reduction of the startup time are the two aims of the trials that additionally dose reactors with, for example, multivalent cations, sludge micropowder, granular sludge and mineral or organic powdered materials (Sarma et al., 2017; Czarnota et al. 2018).

Thus, the work detailed in this paper sought to compare biogranulation in two GSBRs working at different OLR values, albeit both below the values regarded as either optimum or minimum for the AGS technology. Therefore, the trials under those circumstances also investigated the role of supplying powdered ceramsite to reactors, with a view to intensifying biogranulation and helping maintain the granule stability.

\section{METHODS AND MATERIALS}

\section{Reactor set-up and operation}

The research was conducted in laboratory scale for 85 days, with a 4-day initial adaptation period. Two identical GSBRs of $3.0 \mathrm{dm}^{3}$ working volumes were used (Fig. 1).

The height/diameter ratio of each reactor was 11.1 (internal diameter $7.0 \mathrm{~cm}$, working height $78.0 \mathrm{~cm}$ ). The reactors operated on successive 4-hour cycles (30 min - feeding, $195 \mathrm{~min}$ - aerobic reaction, $4 \mathrm{~min}$ - settling, $5 \mathrm{~min}$ - decantation, $6 \mathrm{~min}$ - idle phase), with a volumetric exchange ratio (VER) of $50 \%$, resulting in a hydraulic retention time (HRT) of $8 \mathrm{~h}$. The filling phase saw wastewater introduced through a layer of settled biomass, while the reaction phase featured an aeration rate maintained at $1.83 \mathrm{dm}^{3} / \mathrm{min}$, with air supplied via the diffuser at the bottom of the reactor. Powdered ceramsite (at
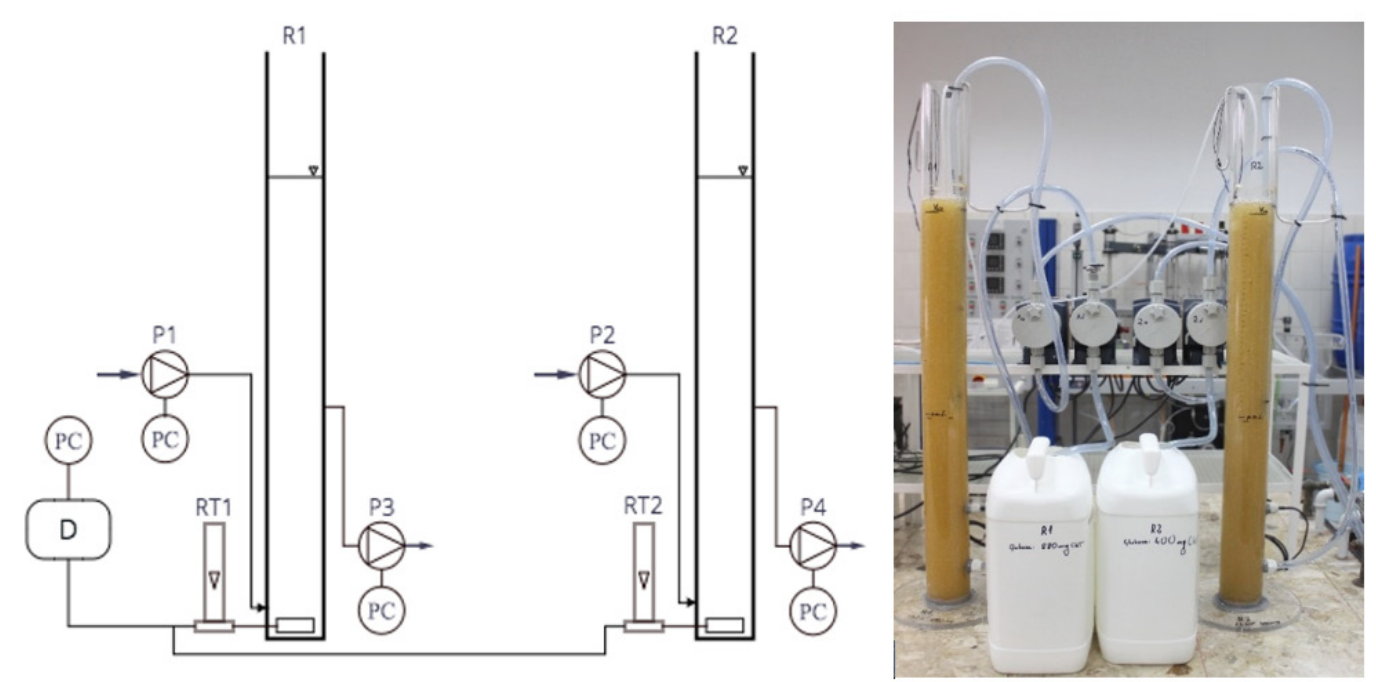

Figure 1. A schematic representation of the experimental set-up: $\mathrm{P} 1$ and $\mathrm{P} 2$ - feeding pump, P3 and P4 - effluent pump, PC - control panel, D - air blower, RT1 and RT2 - rotameter 
$3.0 \mathrm{~g} / \mathrm{dm}^{3}$ ) was supplied to both reactors. The adopted organic loading rate values in the reactors were different. In R1 reactor the OLR was about $2.10 \mathrm{~g} \mathrm{COD} /\left(\mathrm{dm}^{3} \cdot \mathrm{d}\right)$, while in the $\mathrm{R} 2$ reactor, this parameter was $1.0 \mathrm{~g} \mathrm{COD} /\left(\mathrm{dm}^{3} \cdot \mathrm{d}\right)$. GSBRs were operated automatically through time controllers, while operating temperatures in the $20-30^{\circ} \mathrm{C}$ range were maintained.

\section{Seed sludge and characteristics of the influent}

The inoculum was activated sludge from a nitrification tank at the Rzeszów WWTP, with $\mathrm{SVI}_{30}$ of $151 \mathrm{~cm}^{3} / \mathrm{g}$ and MLSS of $5.96 \mathrm{~g} / \mathrm{dm}^{3}$. This was dominated by small flocs that were neither very concise nor of regular shape. A small proportion of the seed sludge had assumed the form of spherical flocs with compact structure. In the trials described here, the volume of inoculum was $1.8 \mathrm{dm}^{3}$ (or $60 \%$ of the working volume of the reactor).

The synthetic wastewater used was one in which the main sources of organic, nitrogen and phosphorus compounds were provided by glucose (at 0.812 and $0.369 \mathrm{~g} \mathrm{C}_{6} \mathrm{H}_{12} \mathrm{O}_{6} / \mathrm{dm}^{3}$ in $\mathrm{R} 1$ and $\mathrm{R} 2$ respectively), ammonium chloride $\left(0.15 \mathrm{~g} \mathrm{NH}_{4} \mathrm{Cl} / \mathrm{dm}^{3}\right)$ and potassium dihydrogen phosphate $\left(0.043 \mathrm{~g} \mathrm{KH}_{2} \mathrm{PO}_{4} / \mathrm{dm}^{3}\right)$, respectively. This composition was in line with that detailed by Thanh et al. (2009). A fuller characterisation of the synthetic wastewater used in this study is provided in Table 1.

\section{Characteristics of powdered ceramsite}

Powdered ceramsite is a waste fraction arising as ceramic aggregates are produced, of natural grain-size in the $0-200 \mu \mathrm{m}$ range $\left(\mathrm{d}_{10}=3.643 \mu \mathrm{m}\right.$; $\left.\mathrm{d}_{50}=24.110 \mu \mathrm{m} ; \mathrm{d}_{90}=85.279 \mu \mathrm{m}\right)$. Otherwise, this material has a specific surface area of $5.183 \mathrm{~m}^{2} / \mathrm{g}$, an apparent density of $2.6182 \mathrm{~g} / \mathrm{cm}^{2}$ and a settling velocity of approx. $9.0 \mathrm{~m} / \mathrm{h}$. Chemically, the material is of a composition dominated by ions of $\mathrm{Si}$ (216.30 mg/g), Ca (75.90 mg/g), Al (46.47 mg/g), $\mathrm{Fe}(45.15 \mathrm{mg} / \mathrm{g})$ and $\mathrm{Mg}(21.61 \mathrm{mg} / \mathrm{g})$. Cations such as $\mathrm{Ca}^{2+}, \mathrm{Mg}^{2+}$ and $\mathrm{Fe}^{3+}$ are regarded as important for biogranulation. The leachable concentrations of substances from the material were $451.65 \mu \mathrm{g} \mathrm{Ca} / \mathrm{g}, 0.50 \mu \mathrm{g} \mathrm{Fe} / \mathrm{g}, 97.87 \mu \mathrm{g} \mathrm{Mg} / \mathrm{g}$ and $23.01 \mu \mathrm{g} \mathrm{Si} / \mathrm{g}$.

\section{Methods of analysis}

Standard methods (after APHA, 2005) were used in determining mixed liquor volatile suspended solids (MLVSS), mixed liquor suspended solids (MLSS), sludge settling velocity (SV), and the sludge volume index after 5 minutes of sedimentation $\left(\mathrm{SVI}_{5}\right)$, or after 30 minutes $\left(\mathrm{SVI}_{30}\right)$. The morphology of sludge flocs and aerobic granules was examined under an Olimpus BX51 optical microscope, while the method proposed by Arrojo (2007) was used to measure sludge flocs and aerobic granules. CellQ image analysis software estimated granule diameters, with once-weekly measurements made on a minimum of 200 granules per reactor. The method with dextran blue was used to determine the biomass density (mass of granules per unit volume) (Beun et al., 2002). However, as powdered mineral materials were being applied, the measurements began on day 15 .

Standard methods (after APHA, 2005) were also applied in determining chemical oxygen demand (COD), the values obtained serving in the calculation of organic loading rate (OLR), as well as the food-to-microorganism ratio (F/M).

\section{Statistical analysis}

The statistical analysis was carried out using STATISTICA 10 PL software. The dependent relationships between two variables (and their statistical significances) were identified by reference to Pearson linear correlations, with a significance level of $\alpha=0.05$ assumed. The Mann-Whitney $\mathrm{U}$ Test served in the evaluation of differences between means. The probability of error relating to the adoption of the hypothesis that means differed was set at $5 \%(\mathrm{p}<0.05)$.

Table 1. Characteristics of the synthetic wastewater

\begin{tabular}{|c|c|c|c|c|c|c|c|}
\hline Reactor & $\begin{array}{c}\mathrm{COD} \\
{\left[\mathrm{mg} \mathrm{O}_{2} / \mathrm{dm}^{3}\right]}\end{array}$ & $\begin{array}{c}\mathrm{NH}_{4}-\mathrm{N} \\
{\left[\mathrm{mg} \mathrm{N} / \mathrm{dm}^{3}\right]}\end{array}$ & $\begin{array}{c}\mathrm{TN} \\
{\left[\mathrm{mg} \mathrm{N} / \mathrm{dm}^{3}\right]}\end{array}$ & $\begin{array}{c}\mathrm{PO}_{4}-\mathrm{P} \\
{\left[\mathrm{mg} \mathrm{P}^{2} / \mathrm{dm}^{3}\right]}\end{array}$ & $\begin{array}{c}\text { TP } \\
{\left[\mathrm{mg} \mathrm{P}^{2} \mathrm{dm}^{3}\right]}\end{array}$ & $\mathrm{COD} / \mathrm{TN}$ & $\mathrm{COD} / \mathrm{TP}$ \\
\hline $\mathrm{R} 1$ & $862.8 \pm 31.0$ & \multirow{2}{*}{$36.4 \pm 1.8$} & \multirow{2}{*}{$42.2 \pm 1.6$} & \multirow{2}{*}{$8.65 \pm 0.19$} & \multirow{2}{*}{$9.35 \pm 0.20$} & $20.5 \pm 1.3$ & $92.3 \pm 2.7$ \\
\hline $\mathrm{R} 2$ & $408.9 \pm 12.9$ & & & & & $9.7 \pm 0.5$ & $43.7 \pm 1.5$ \\
\hline
\end{tabular}




\section{RESEARCH RESULTS AND DISCUSSION}

\section{The biogranulation process}

The reactor operating at higher OLR was characterised by a more-intensive shaping of granules (Fig. 2).

On day 15 of the research, granules accounted for $15 \%$ of the R1 reactor and $12 \%$ of the $\mathrm{R} 2$ reactor. By day 29, the percentage of granular biomass in R1 was already approaching $48 \%$. In turn, in the $\mathrm{R} 2$ reactor, the proportion of granules only increased significantly between day 29 and day 36 , by which time $76 \%$ of granular biomass was of the $200 \div 400 \mu \mathrm{m}$ size fraction. In the R1 reactor, operating with an OLR equal to $2.10 \mathrm{~g} \mathrm{COD} /\left(\mathrm{dm}^{3} \cdot \mathrm{d}\right)$, an increase in the proportion of granules achieving larger diameters was observed on subsequent days of the study. Moreover, no significant increase in the proportion of smaller granules was observed in this reactor in the course of the work, attesting to the stability of the aggregates cultivated. In R1, full biogranulation was observed after 50 days, while by day 85 , more than $50 \%$ of all granules were larger than $1000 \mu \mathrm{m}$. In contrast, in the R2 reactor with an OLR of $1.0 \mathrm{~g}$ $\mathrm{COD} /\left(\mathrm{dm}^{3} \cdot \mathrm{d}\right)$, the aggregates of 200 to $400 \mu \mathrm{m}$ dominated from day 36 onwards. In this reactor, it was only after day 71 that the biomass of flocs smaller than $200 \mu \mathrm{m}$ accounted for less than $20 \%$ of the total. Through to day 43 of research, mean granule sizes in the two reactors were comparable (at 298.46 and $245.60 \mu \mathrm{m}$, respectively). Thereafter, the granules of much greater size were observed in the reactor fed with wastewater with a higher concentration of organic compounds.

In the presence of low OLR values, the support for biogranulation in the form of powdered ceramsite was seen to make the appearance of aerobic granules possible. The aggregates cultivated in the R2 reactor were of smaller diameters than the granules obtained under comparable technological conditions, but with granular activated carbon (GAC) added. Li et al. (2011) conducted a study with an OLR of $0.80 \mathrm{~g} \mathrm{COD/}$ $\left(\mathrm{dm}^{3} \cdot \mathrm{d}\right)$, dosing their reactor with $3.0 \mathrm{~g} / \mathrm{dm}^{3}$ GAC of grain size of approx. $224 \mu \mathrm{m}$. Those authors reported a day-70 mean granule size of around $350 \mu \mathrm{m}$. In turn, Tao et al. (2017) studied biogranulation where OLR was of approx. $1.0 \mathrm{~g}$ $\mathrm{COD} /\left(\mathrm{dm}^{3} \cdot \mathrm{d}\right)$, and dosing with GAC of $125-300$ $\mu \mathrm{m}$ grain size (14.5 $\mathrm{g} /$ reactor volume). By day 60 of their work, those authors had obtained the granules of mean size around $500 \mu \mathrm{m}$ (compared with $\leq 200 \mu \mathrm{m}$ up to day 30 ).

In our work, microscopic imaging revealed ceramsite particles present within the structure of activated sludge flocs and granules. The ceramsite grains were present in the entire volume of the reactor and uniform suspension of powdered ceramsite with biomass was observed. The formation of granules containing ceramsite microparticles was also noted (Fig. 3).

\section{Role of OLR and F/M on biogranulation process}

The values for organic loading rate adopted in the work detailed here were below the values considered optimal for the AGS technology. In the R1 reactor, there was a highly significant correlation
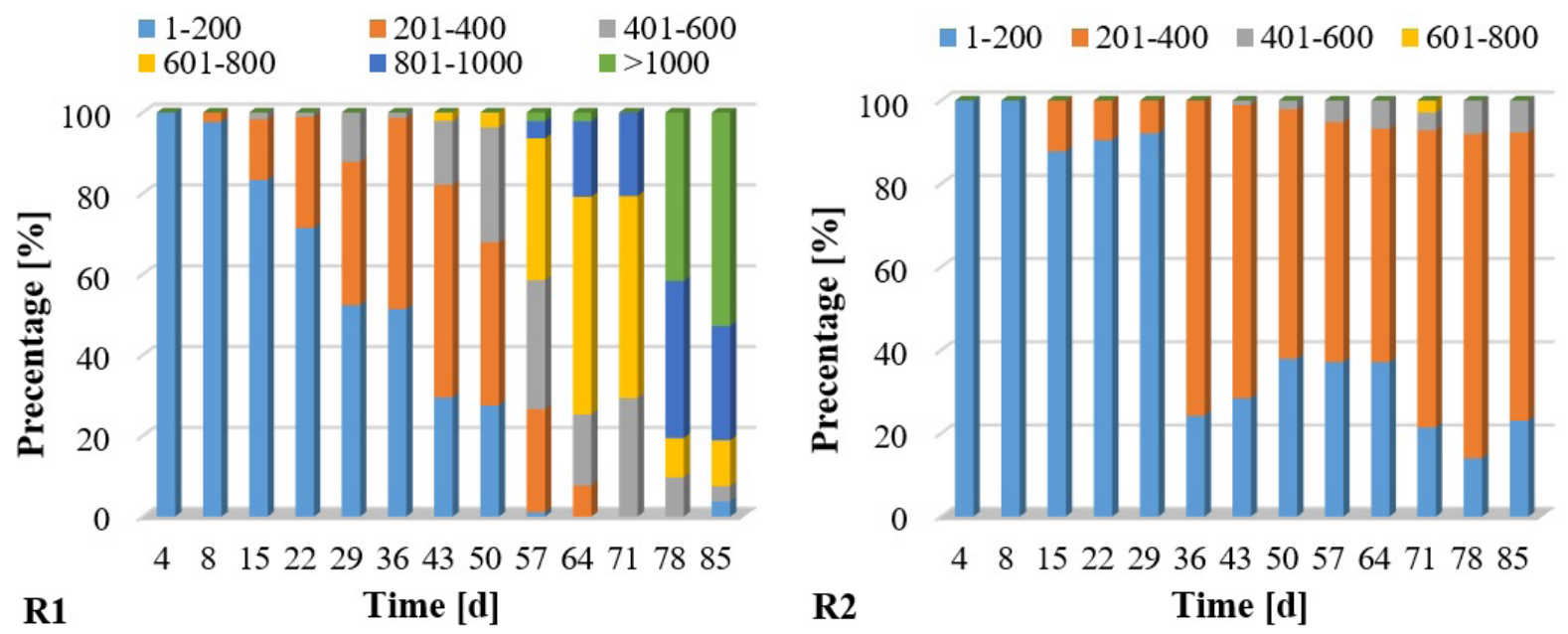

Figure 2. The biogranulation process - percentages of granules in the assumed diameter ranges 

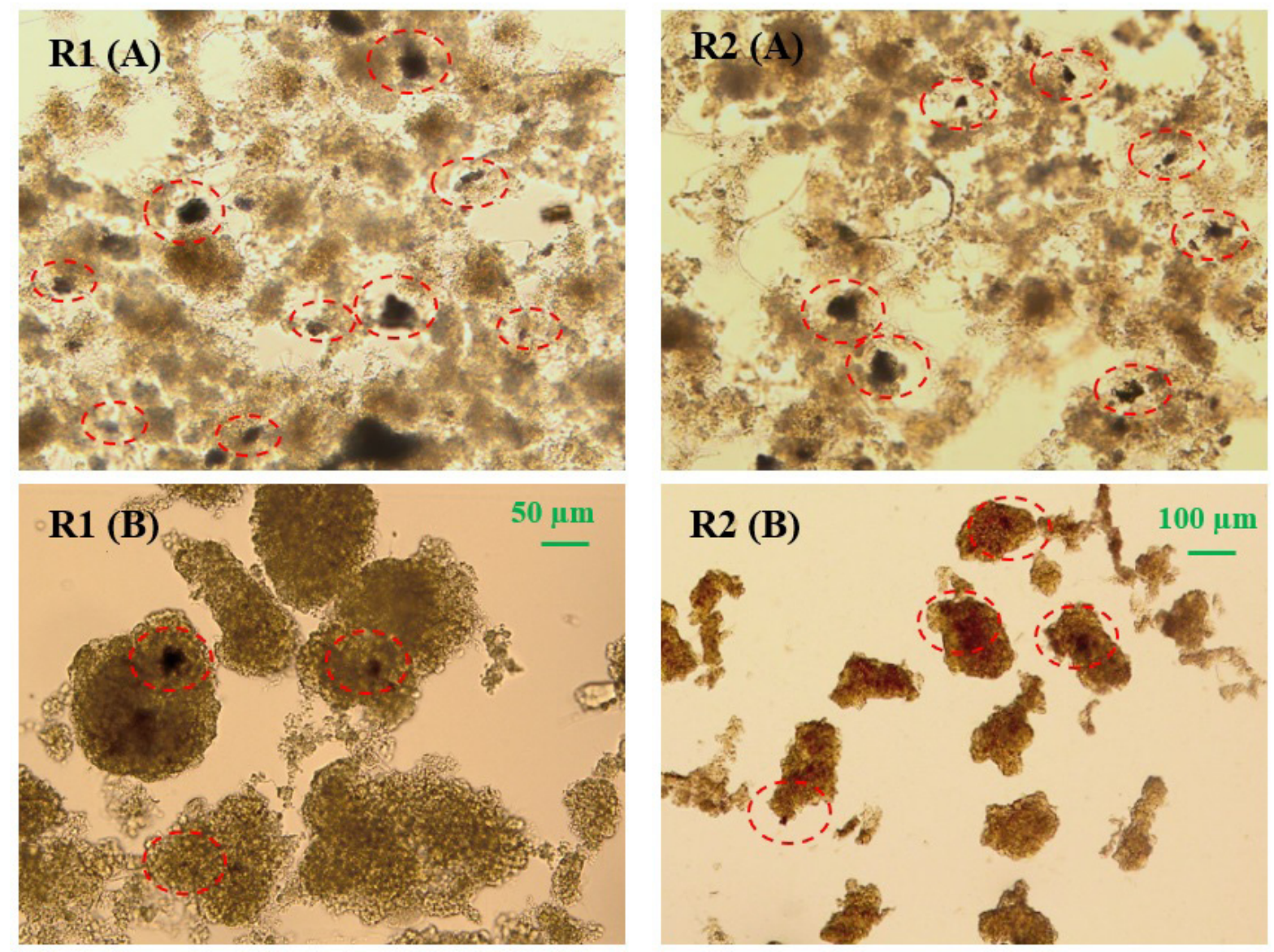

Figure 3. Powdered ceramsite in floc and granule structure $\left(A-4^{\text {th }}\right.$ day of research, $B-36^{\text {th }}$ day of research $)$

between a slightly-greater OLR and greater growth of granules $(\mathrm{p}<\alpha, \mathrm{p}=0.0015)$. A moderate positive correlation between these parameters was observed for the R2 reactor. The analysis showed no significant effect on biogranulation of an OLR value equal to $1.0 \mathrm{~g} \mathrm{COD} /\left(\mathrm{dm}^{3} \cdot \mathrm{d}\right)(\mathrm{p}>\alpha$, $\mathrm{p}=0.2527$ ) (Fig. 4a). Such results lead to a conclusion that a load of $2.10 \mathrm{~g} \mathrm{COD} /\left(\mathrm{dm}^{3} \cdot \mathrm{d}\right)$ - slightly below the minimum value deemed optimal - also makes the granule formation possible.

Tao et al. (2017) also showed that low loading with organic compounds, i.e. about $1.0 \mathrm{~g} \mathrm{COD} /\left(\mathrm{dm}^{3} \cdot \mathrm{d}\right)$ was partly responsible for a longer granulation time (of 61 days). The particles of GAC they applied were shown to accelerate this process, constituting a biomass microcarrier.

In both of our reactors, the sludge organic load (F/M ratio) influenced biogranulation significantly. The values for this parameter were in the 0.340-0.909 $\mathrm{g} \mathrm{COD} /(\mathrm{g}$ MLVSS $\cdot \mathrm{d})$ range in $\mathrm{R} 1$, and between 0.252 and $0.497 \mathrm{~g} \mathrm{COD} /(\mathrm{g}$ MLVSS$\cdot \mathrm{d}$ ) in R2. The correlation between F/M and granule growth was an inverse high one in R1 and an inverse very high one in R2. In both reactors, the relationship between these parameters achieved significance $(p<\alpha, p=0.0199$ for $R 1$ and $p=0.0001$ for R2). Thus, the results show that - with the technological parameters adopted - granule formation is more favoured where the values for COD loading of sludge were lower (Fig. 4b). The support for biogranulation an addition of powdered ceramsite can offer, where technological parameters are unfavourable, can thus be regarded as a positive influence, when it comes to the formation of aerobic granules in association with improved sludge sedimentation properties and reduced leaching of biomass.

Mean diameter of granules reported by us for day 85 in the R1 reactor was $960 \mu \mathrm{m}$. Czarnota et al. (2018) reported mean size of granules equal $780 \mu \mathrm{m}$ in a reactor with the addition of powdered ceramsite on the $89^{\text {th }}$ day of the study. The ORL in R1 was lower than that applied by Czarnota et al. (around $2.55 \mathrm{~g} \mathrm{COD} /\left(\mathrm{dm}^{3} \cdot \mathrm{d}\right)$, while the COD of their raw wastewater was $717.1 \pm 62.6 \mathrm{mg} \mathrm{O}_{2} / \mathrm{dm}^{3}$. Such results suggest that it was the higher concentration of organic compounds in the wastewater fed to our R1 reactor that resulted in the formation of larger granules. 

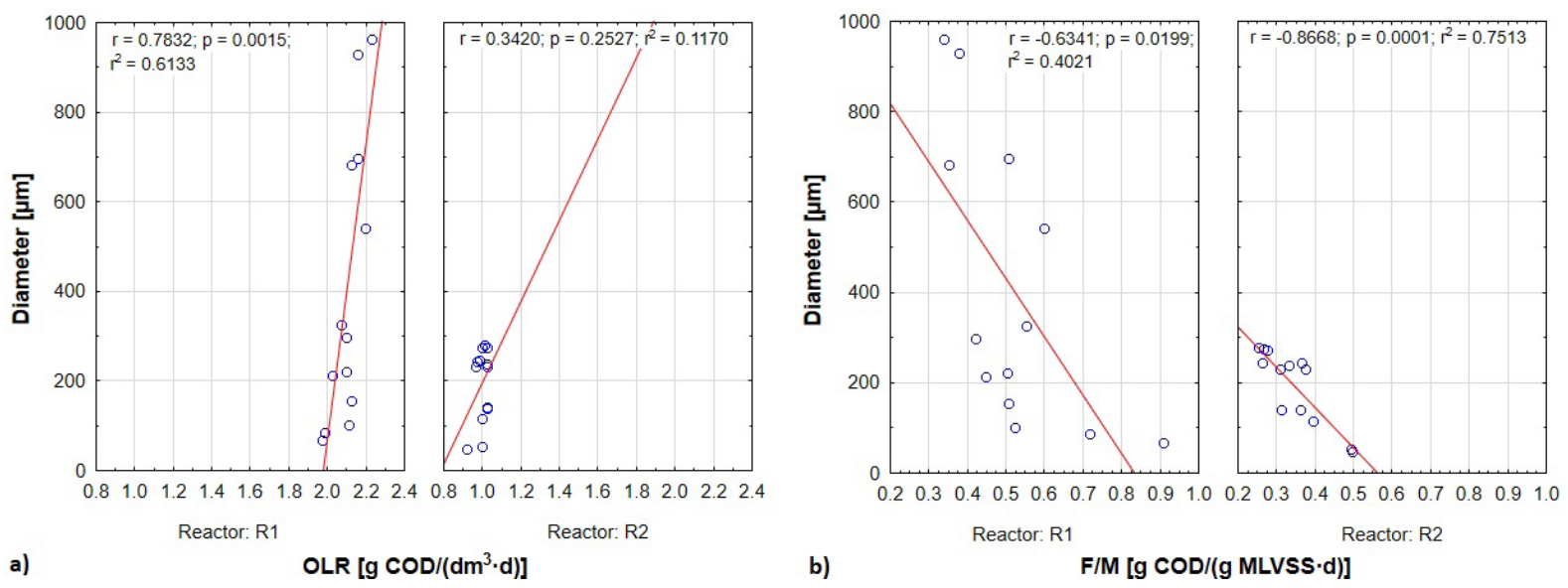

Figure 4. The effect of OLR on granule formation (a) and the relationship between F/M and granule growth (b)

The granules in our R1 reactor were also larger than those obtained by Wei et al. (2010), who supported their biogranulation process with powdered activated carbon (PAC) at an OLR of about $2.10 \mathrm{~g} \mathrm{COD} /\left(\mathrm{dm}^{3} \cdot \mathrm{d}\right)$. In turn, Wei et al. (2013) observed that the microorganisms attached to the surface of the zeolite (of $200 \mu \mathrm{m}$ mean grain size) that formed their floc-zeolite structure. In turn, their OLR was of about $1.80 \mathrm{~g} \mathrm{COD} /\left(\mathrm{dm}^{3} \cdot \mathrm{d}\right)$. There are also reports in the literature of powdered materials allowing granular biomass to be obtained in a very short time. He et al. (2016) obtained mature granules from $700-1300 \mu \mathrm{m}$ in diameter as early as on day 4 . Those authors ran their study with a load of approx. $1.80 \mathrm{~g} \mathrm{COD} /\left(\mathrm{dm}^{3} \cdot \mathrm{d}\right)$, also deploying yellow earth of ca. $270 \mu \mathrm{m}$ grain size in support of the biogranulation process. $\mathrm{He}$ et al. (2016) suggested that rapid biogranulation could be achieved using a powdered material of high silicon and aluminium content and greater grain size.

\section{Selected physical properties of biomass}

Once the system had been inoculated with activated sludge, the MLSS concentration in the reactors reached a level of about $3.80 \mathrm{~g} / \mathrm{dm}^{3}$. In turn, the application of powdered ceramsite (at $3.0 \mathrm{~g} / \mathrm{dm}^{3}$ ) raised the value further to approx. 7.23 and $7.13 \mathrm{~g}$ MLSS/ $/ \mathrm{dm}^{3}$ in R1 and R2 reactors, respectively. The material with biomass was evenly suspended in both reactors. On the day of system startup, The MLVSS concentrations were of $3.34 \mathrm{~g} / \mathrm{dm}^{3}$ in the R1 reactor and $3.0 \mathrm{~g} / \mathrm{dm}^{3}$ in R2. In turn, the respective contents of mineral substances were 3.89 and $4.13 \mathrm{~g} / \mathrm{dm}^{3}$. Time adaptation of the system saw MLSS values in the reactors decreased by about $51 \%$. In contrast, the MLVSS values decreased by approx. $35 \%$ (in R1) and 38\% (in R2). Subsequently, the biomass concentrations were of $3.49 \div 7.48 \mathrm{~g}$ and $3.50 \div 5.16 \mathrm{~g} \mathrm{MLSS} / \mathrm{dm}^{3}$ in R1 and R2 (Fig. 5a), while the MLVSS values ranged from 2.17 to 6.56 (R1) and from 1.85 to $4.01 \mathrm{~g} / \mathrm{dm}^{3}$ (R2). The values for the MLVSS/MLSS ratio thus oscillated between 0.62 and 0.88 in R1 and 0.53 and 0.82 in R2 (Fig. 5a). The obtained values for the ratio show the share of mineral parts in biomass. A lower coefficient for the changes in biomass concentration, and thus higher stability, was observed in the $\mathrm{R} 2$ reactor.

Our two reactors differed in a statistically significant manner, in relation to both MLSS and MLVSS $(p<\alpha, p=0.0056$ and $p=0.0020$, respectively). These differences were mainly due to the organic loading rates assumed, which were of around $2.10 \mathrm{~g} \mathrm{COD} /\left(\mathrm{dm}^{3} \cdot \mathrm{d}\right)$ in $\mathrm{R} 1$ and $1.0 \mathrm{~g} \mathrm{COD} /\left(\mathrm{dm}^{3} \cdot \mathrm{d}\right)$ in $\mathrm{R} 2$.

Following the inoculation of reactors and application of powdered ceramsite, the $\mathrm{SVI}_{30}$ values were of $91.3 \mathrm{~cm}^{3} / \mathrm{g}(\mathrm{R} 1)$ and $70.1 \mathrm{~cm}^{3} / \mathrm{g}(\mathrm{R} 2)$. However, in the course of research, the values oscillated between 16.6 and $57.1 \mathrm{~cm}^{3} / \mathrm{g}$ and between 26.5 and $62.0 \mathrm{~cm}^{3} / \mathrm{g}$ (Fig. 5b). The reactor operating at lower OLR showed slightly greater stability of the sludge volume index, with differences in average values nevertheless achieving $p<\alpha$ statistical significance $(p=0.0312)$. Our results for $\mathrm{SVI}_{30}$ are comparable with those presented by $\mathrm{Li}$ et al. (2011). In their reactor dosed with GAC, day 25 brought an $\mathrm{SVI}_{30}$ value of around $37 \mathrm{~cm}^{3} / \mathrm{g}$. On the other hand, with their GAC-dosed reactor, Tao et al. (2017) had a day-30 sludge volume index almost three times as high as the one noted in our own work. 

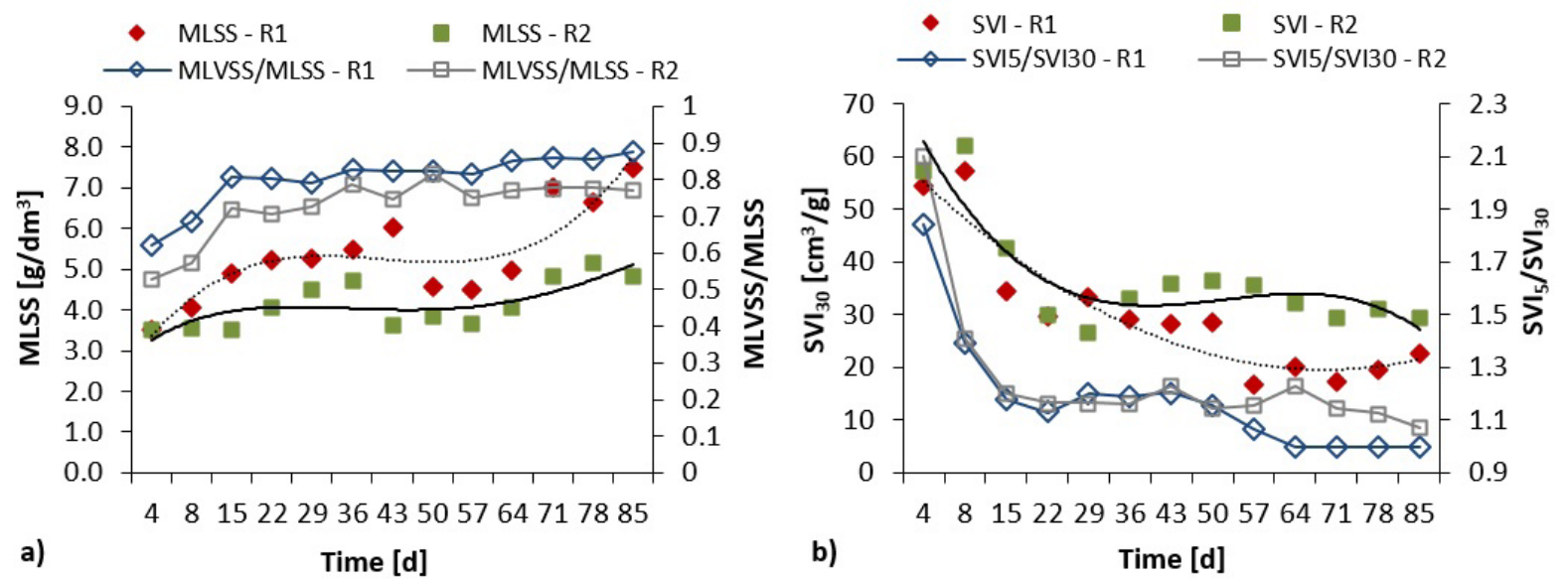

Figure 5. Profile for MLSS and MLVSS/MLSS (a) and for $\mathrm{SVI}_{30}$ and $\mathrm{SVI}_{5} / \mathrm{SVI}_{30}$ (b)

Under the technological paramaters adopted, the application of powdered ceramsite served to limit the leaching of biomass, with the sludge organic load (F/M) reduced, and sedimentation properties of the sludge improved as a consequence. A more-favourable $\mathrm{SVI}_{30}$ was observed where values for F/M were lower (Fig. 6a).

Our reactors were found to be characterised by a high inverse correlation between the decreasing $\mathrm{SVI}_{5} / \mathrm{SVI}_{30}$ ratio and increasing floc size (in the initial days of the study) or by the increasing granule size (in the further course of the experiment). The relationships achieved statistical significance in both the $\mathrm{R} 1$ and $\mathrm{R} 2$ reactors $(\mathrm{p}<\alpha$, $p=0.0109$ and $p=0.0107$ respectively) (Fig. 6b).

The dosing of GSBR reactors with powdered ceramsite provided for increased biomass settling velocities - of $14.5 \pm 7.8 \mathrm{~m} / \mathrm{h}(\mathrm{R} 1)$ and $9.2 \pm 2.7 \mathrm{~m} / \mathrm{h}(\mathrm{R} 2)$. The $\mathrm{R} 1$ reactor operating at a higher OLR (Fig. 7a) had a significantly higher settling velocity, albeit with this parameter proving highly variable. The higher values for settling velocity in this reactor were mainly due to the presence of granules of greater diameter. The Mann Whitney U-test did not show significant differences for average settling-velocity values $(p>\alpha$, $p=0.0905)$. However, in both reactors, the relationship between settling velocity and granule diameter was shown to be statistically significant $(\mathrm{p}<\alpha$, $\mathrm{p}=0.0000$ for $\mathrm{R} 1$ and $\mathrm{p}=0.0002$ for R2) (Fig. 7b).

The granule densities achieved during study were higher in the reactor operating at a higher OLR, with the average values for this parameter (from day 15) being $32.74 \pm 7.74 \mathrm{~g}$ MLVSS $/ \mathrm{dm}^{3}$ granules (R1) and $23.23 \pm 2.91 \mathrm{~g} \mathrm{MLVSS} / \mathrm{dm}_{\text {granules }}^{3}$ (R2). Thereafter, the density achieved by biomass increased slowly. Both reactors exhibited significant increases in average diameters of granules (after 50 days in R1 and 29 days in R2), as well as a greater increase in the granule density. The values noted for biomass density in R1 resulted mainly from
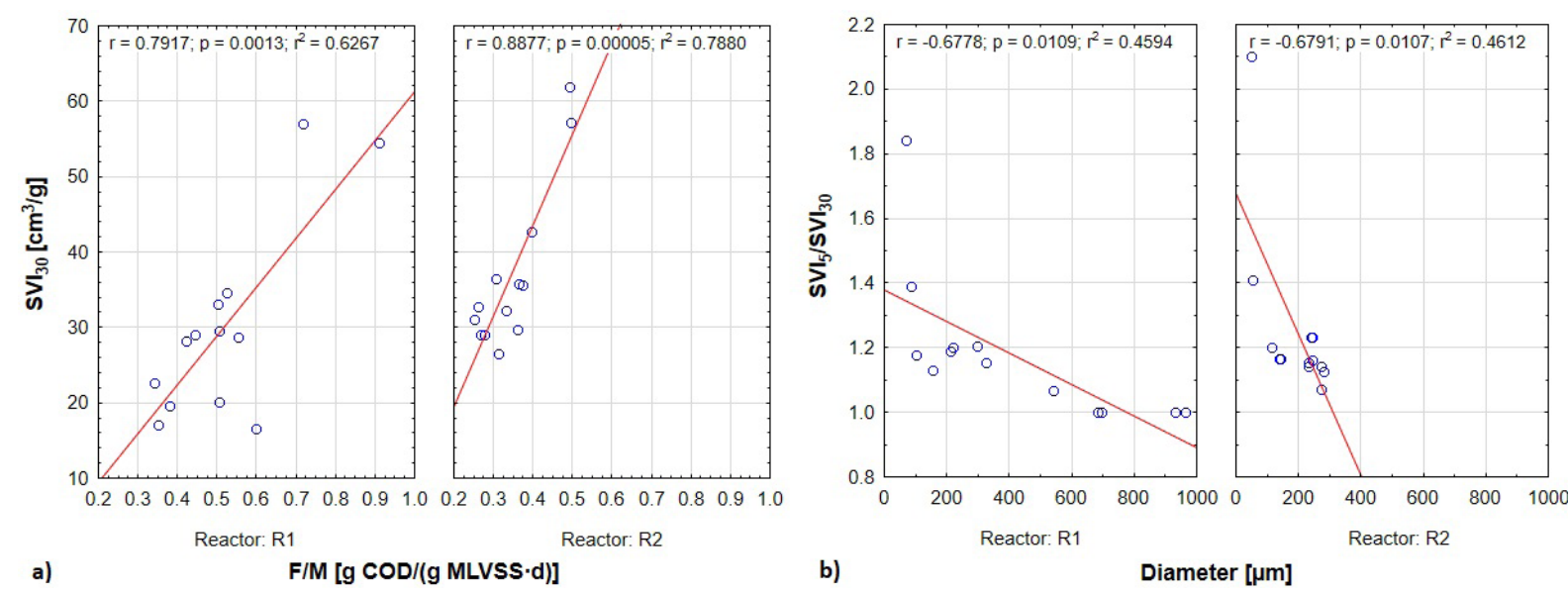

Figure 6. Scatter graph showing the dependent relationship between F/M and $\mathrm{SVI}_{30}$

(a) or diameter of granules and $\mathrm{SVI}_{5} / \mathrm{SVI}_{30}$ (b) 

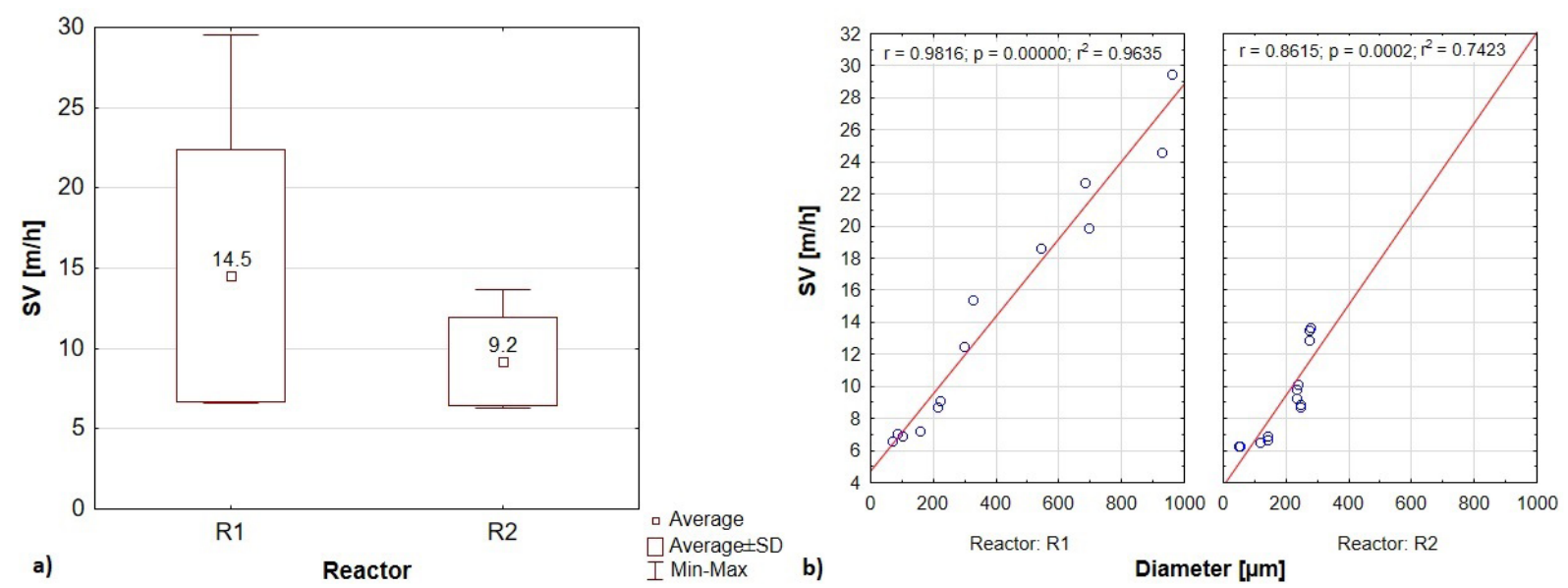

Figure 7. Average values for settling velocity (a) and the relationship between SV and granule diameter (b)
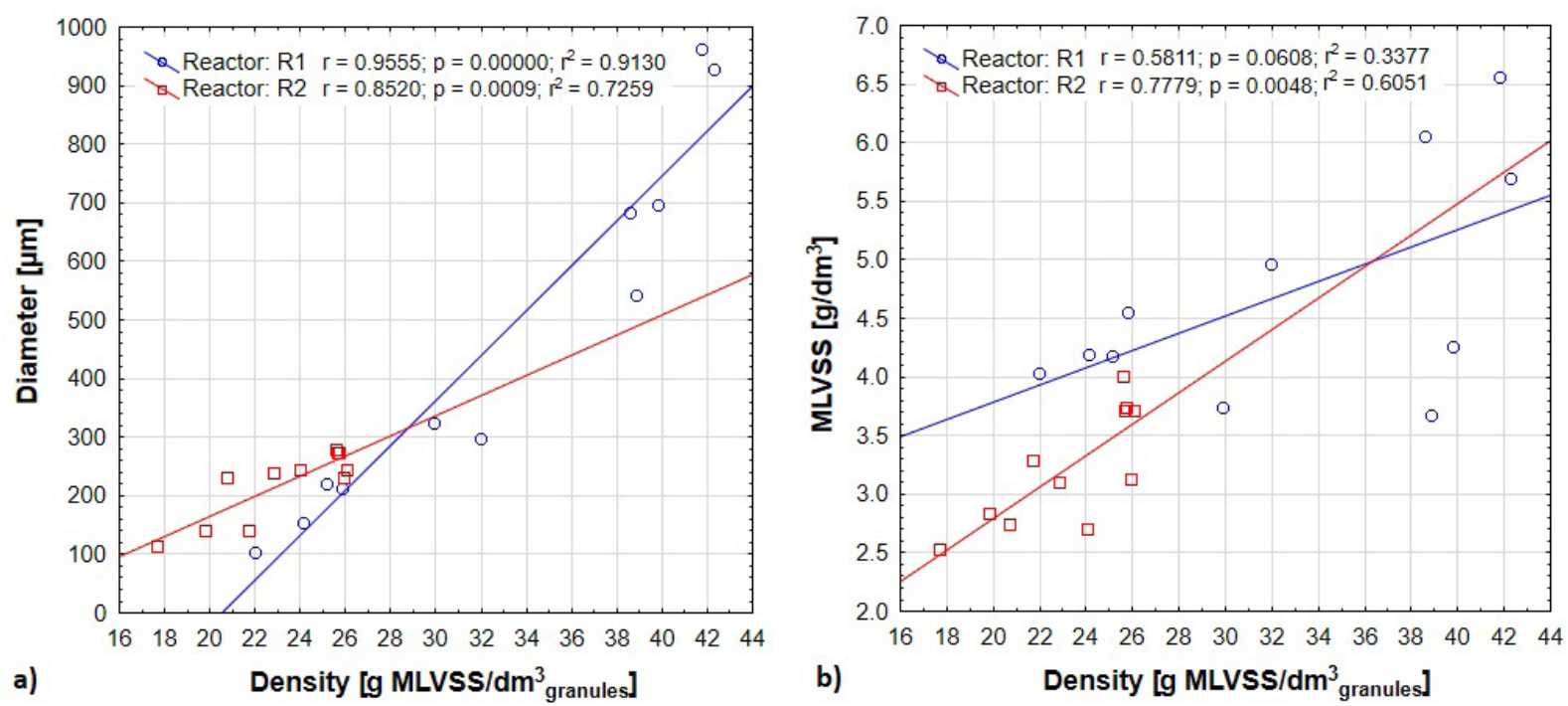

Figure 8. Scatter graph showing the dependent relationship between density of biomass and diameter of granules (a) or MLVSS (b)

a higher concentration of MLVSS, and the size of aggregates (Fig. 8a and 8b).

Minh (2006) also observed an increase in the granule density along with the increasing diameter. In turn, the research carried out by CydzikKwiatkowska et al. (2013) showed that the highest concentration of microorganisms in granule structure was achieved by aggregates not larger than $1.0 \mathrm{~mm}$. Granules of less than $1.0 \mathrm{~mm}$ achieved the biomass density of up to $30 \mathrm{~g} / \mathrm{dm}^{3}$, with these values decreasing as size increased further (with $4.0 \mathrm{~mm}$ granules for example characterised by density stabilised at $2.0 \mathrm{~g} / \mathrm{dm}^{3}$ ). The authors stress how the reactor processes like nitrification and simultaneous nitrification-denitrification favoured the appearance of high-density granules, as nitrifiers form tightly-packed consortia within biomass, with nitrification generating the electron acceptors supportive of bacterial growth within granules. The granules in our R2 reactor had much smaller diameters than the biomass in R1. However, the results obtained for biomass density in the two reactors were in the range of $10-120 \mathrm{~g} \mathrm{MLVSS} / \mathrm{dm}^{3}$ granules [Nor-Anuar et al., 2012], and such values typify hard, compact granules. It should be noted that this is one of the five reference parameters used to assess the physical strength of aerobic granules [NorAnuar et al., 2012].

\section{CONCLUSIONS}

The addition of powdered ceramsite to the reactors operating at the OLR values of $2.10 \mathrm{~g} \mathrm{COD} /$ $\left(\mathrm{dm}^{3} \cdot \mathrm{d}\right)$ and $1.0 \mathrm{~g} \mathrm{COD} /\left(\mathrm{dm}^{3} \cdot \mathrm{d}\right)$ provided for biogranulation, even if granule sizes differed greatly. The results show unequivocally that an organic loading rate of around $2.10 \mathrm{~g} \mathrm{COD} /\left(\mathrm{dm}^{3} \cdot \mathrm{d}\right)$ will sustain granule formation, despite this value being widely regarded as sub-optimal. However, in both 
reactors, the biogranulation process was determined by the more-limited loading of sludge with organic compounds $(\mathrm{F} / \mathrm{M})$, as a reflection of higher biomass concentrations in the reactors. The application of powdered ceramsite influenced the achievement of higher MLVSS values directly, due to improved sludge-sedimentation properties (reflected in values for $\mathrm{SVI}_{5}, \mathrm{SVI}_{30}$ and SV), with more-limited leaching of biomass observed in consequence during the settling phase. The powdered ceramsite acted as ballast for sludge flocs, with sedimentation properties of biomass improved, as well as a microcarrier of biomass that gains incorporation into the floc/granule structure.

Moreover, reference to the literature indicates that the concentration of organic compounds present in the wastewater supplied to a reactor is one of the main factors influencing the process of granular-biomass formation.

\section{REFERENCES}

1. APHA, 2005. Standard Methods for the Examination of Water and Wastewater, 21st ed. American Public Health Association, Washington DC, USA.

2. Arrojo B. 2007. Advanced systems for biological treatment of high nitrogen - loaded wastewater. Pd.D. Thesis, Uniwersytet Santiago de Compostela.

3. Beun J.J., van Loosdrecht M.C.M., Heijnen J.J. 2002. Aerobic granulation in a sequencing batch airlift reactor. Water Research, 36, 702-712.

4. Cydzik-Kwiatkowska A., Wojnowska-Baryła I., Szatkowski M., Smoczyński L. 2013. Biochemical conversions and biomass morphology in a longterm operated SBR with aerobic granular sludge. Desalination and Water Treatment, 51, 2261-2268.

5. Czarnota J., Masłoń A., Zdeb M. 2018. Powdered keramsite as unconventional method of AGS technology support in GSBR reactor with minimumoptimum OLR. E3S Web of Conferences 44, 00024, https://doi.org/10.1051/e3sconf/20184400024.

6. Derlon N., Wagner J., da Costa R.H.R., Morgenroth E. 2016. Formation of aerobic granules for the treatment of real and low-strength municipal wastewater using a sequencing batch reactor operated at constant volume. Water Research, 105, 341-350.

7. He Q.L., Zhang S.L., Zou Z.C., Wang H.Y. 2016. Enhanced formation of aerobic granular sludge with yellow earth as nucleating agent in a sequencing batch reactor. IOP Conf. Series: Earth and Environmental Science, 39, 1-10.

8. Kim I.S., Kim S.M., Jang A. 2008. Characterization of aerobic granules by microbial density at different COD loading rates. Bioresource Technology, 99, 18-25.
9. Li A.J., Li X.Y., Yu H.Q. 2011. Granular activated carbon for aerobic sludge granulation in a bioreactor with a low-strength wastewater influent. Separation Purification Technology, 80, 276-283.

10. Long B., Xuan X., Yang Ch., Zhang L., Cheng Y., Wang J. 2019. Stability of aerobic granular sludge in a pilot scale sequencing batch reactor enhanced by granular particle size control. Chemosphere, 225, 460-469.

11. Minh N.D. 2006. Treatment of high-strength organic wastewater using an aerobic granular system with baffled membrane bioreactor. MsC Thesis, Asian Institute of Technology.

12. Nor-Anuar A., Ujang Z., van Loosdrecht M.C.M., de Kreuk M.K., Olsson G. 2012. Strength characteristics of aerobic granular sludge. Water Science and Technology, 65, 309-316.

13. Sarma S.J., Tay J.H., Chu A. 2017. Finding knowledge gaps in aerobic granulation technology. Trends in Biotechnology, 35(1), 66-78.

14. Sguanci S., Lubello C., Caffaz S., Lotti T. 2019. Long-term stability of aerobic granular sludge for the treatment of very low-strength real domestic wastewater. Journal of Cleaner Production, 222, 882-890.

15. Sheng G.P., Li A.J., Li X.Y., Yu H.Q. 2010. Effects of seed sludge properties and selective biomass discharge on aerobic sludge granulation. Chemical Engineering Journal, 160, 108-114.

16. Tao J., Qin L., Liu X., Li B., Chen J., You J., Shen Y., Chen H. 2017. Effect of granular activated carbon on the aerobic granulation of sludge and its mechanism. Bioresource Technology, 236, 60-67.

17. Thanh B.X., Visvanathan Ch., Aim R.B. 2009. Characterization of aerobic granular sludge at various organic loading rates. Process Biochemistry, 44, 242-245.

18. Wei Y., Ji M., Li G., Qin F. 2010. Powdered activated carbon (PAC) addition for enhancement of aerobically grown microbial granules treating landfill leachate. 2nd Conference ESIAT, 805-808.

19. Wei D., Xue X., Chen S., Zhang Y., Yan L., Wei Q., Du B. 2013. Enhanced aerobic granulation and nitrogen removal by the addition of zeolite powder in a sequencing batch reactor. Environmental Biotechnology, 97, 9235-9243.

20. Zhang H., Dong F., Jiang T., Wei Y., Wang T., Yang F. 2011. Aerobic granulation with low strength wastewater at low aeration rate in $\mathrm{A} / \mathrm{O} / \mathrm{A} \mathrm{SBR}$ reactor. Enzyme and Microbial Technology, 49 (2), 215-222.

21. Zhou J., Zhao H., Hu M., Yu H., Xu X., Vidonish J. 2015. Granular activated carbon as nucleating agent for aerobic sludge granulation: Effect of GAC size on velocity field differences (GAC versus flocs) and aggregation behavior. Bioresource Technology, 198, 358-363.

22. Zou J., Pan J., Wu S., Qian M., He Z., Wang B., Li J. 2019. Rapid control of activated sludge bulking and simultaneous acceleration of aerobic granulation by adding intact aerobic granular sludge. Science of the Total Environment, 674, 105-113. 